\title{
The Stakes Are Higher Than Ever for Delivery of Quality Care
}

\author{
Charles N. Cornell, MD
}

Received: 1 April 2016/Accepted: 14 April 2016/Published online: 5 May 2016

(C) Hospital for Special Surgery 2016

The pace of change in the healthcare market place is accelerating rapidly. What appeared to be a distant storm on the horizon a few years ago is now a raging tempest that threatens to cast us upon a leeward shore. Just the fact that I refer to healthcare as a market place reflects a fundamental change. I would have never imagined in my youth that I would refer to the practice of medicine as an element of a complex, highly regulated, nationwide industry.

Many of the current changes in the market place focus on improving care to diminish cost. The responsibility for these changes is being placed on hospitals and practitioners. Reimbursement is now directly affected by unanticipated or unplanned costs incurred by the complications of post-op care that require readmission or increased levels of care. Hospitals and practitioners involved in orthopedic surgical care have seemingly been singled out in this due to the high volume of procedures that we are currently performing as well as what is expected to be performed in the future. This burden to the practitioner is made heavier by the fact that simultaneously reimbursement has been decreased while overhead costs are increased challenging the viability of surgical practice.

To survive, we must join forces and work as a cohesive team. Co-management of surgical practice is a proven adaptation. Surgeons must use their nonsurgical colleagues to help in delivery of care. Patients must be better prepared for surgery especially if they are high risk. However, post-op care cannot be relegated to nonsurgical specialists. The challenge is to provide surgeons with the resources they need to be able to maintain personalized contact with their patients in the post-op period as they continue to perform a high volume of procedures. Practitioners will be aided by improved communication of new ideas regarding care delivery that are supported by reliable clinical research.

During the 1990s and beginning of the twenty-first century, the HIV-AIDS crisis was the focus of an incredible research effort that has resulted in truly remarkable new therapies. During that period, researchers created new methods of communication to report their findings. Traditional reporting in scientific journals was often modified to provide rapid publication of important new developments. In many respects, the crisis we are facing in adapting to quality-driven care would benefit from a similar, rapid dissemination of new information. The editorial board of HSS Journal is actively working to decrease the time that it takes to publish relevant clinical research that addresses this effort. We will welcome your contributions in this regard.

We hope you find volume 12 issue 2 worthy and useful. There are several articles that address quality and clinical care. Finally, do not miss the well-deserved tribute to our friend and colleague Sam Delgado as he embarks on the exciting next stage of his remarkable life.

\section{Compliance with Ethical Standards}

Conflict of Interest: Charles N. Cornell, MD has declared that he has no conflict of interest.

Human/Animal Rights: This article does not contain any studies with human or animal subjects performed by the any of the authors.

Informed Consent: N/A

Required Author Forms Disclosure forms provided by the authors are available with the online version of this article. 